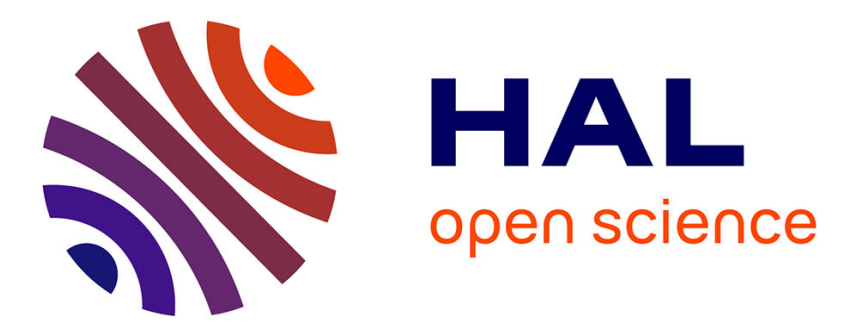

\title{
Contribution in the evaluation of a performance index of hot forging dies
}

\author{
Youcef Bendjoudi, Eric Becker, Régis Bigot, Abdelaziz Amirat
}

\section{To cite this version:}

Youcef Bendjoudi, Eric Becker, Régis Bigot, Abdelaziz Amirat. Contribution in the evaluation of a performance index of hot forging dies. International Journal of Advanced Manufacturing Technology, 2016, 15p. 10.1007/s00170-016-8829-4 . hal-01345149

\author{
HAL Id: hal-01345149 \\ https://hal.science/hal-01345149
}

Submitted on 13 Jul 2016

HAL is a multi-disciplinary open access archive for the deposit and dissemination of scientific research documents, whether they are published or not. The documents may come from teaching and research institutions in France or abroad, or from public or private research centers.
L'archive ouverte pluridisciplinaire HAL, est destinée au dépôt et à la diffusion de documents scientifiques de niveau recherche, publiés ou non, émanant des établissements d'enseignement et de recherche français ou étrangers, des laboratoires publics ou privés. 


\title{
Contribution in the evaluation of a performance index of hot forging dies
}

\author{
Youcef Bendjoudi $^{1} \cdot$ Eric Becker $^{2} \cdot$ Régis Bigot $^{2} \cdot$ Abdelaziz Amirat $^{3}$
}

\begin{abstract}
The present paper focuses on a new concept of evaluation of a performance index of hot forging dies through the combination of a process behaviour model and a reliability approach analysis of the forging process. The process behaviour is modelled and simulated using the computer-aided engineering FORGE ${ }^{\circledR}$ tool that allowed optimizing the forging parameters and determining the stresses and strains together with temperatures during the forging process and also identifying the factors affecting the die life. The respective reliability mechanical model is developed and reliability simulations have been conducted using PHIMECASoft tool in order to evaluate the reliability index $\beta$ and determine the sensitivity of the variations in the random values of the input parameters of the forging process. The concept of this contribution has
\end{abstract}

Youcef Bendjoudi

bendjoudi_y@yahoo.fr

Eric Becker

eric.becker@ensam.eu

Régis Bigot

regis.bigot@ensam.eu

Abdelaziz Amirat

abdelaziz.amirat@univ-annaba.dz

1 Mechanics of Materials and Plant Maintenance Research Laboratory (LR3MI), Faculty of Engineering Sciences, Badji Mokhtar University Annaba, Annaba, Algeria

2 LCFC, Laboratoire de Conception Fabrication et Commande, Arts et Métiers Paristech, Ecole Nationale Supérieure d'Arts et Métiers, 4, rue Augustin Fresnel; Metz Technopole, 57078 Metz Cedex 3, France

3 Research Laboratory of Advanced Technology in Mechanical Production, Faculty of Engineering Sciences, Badji Mokhtar University Annaba, Annaba, Algeria been applied to real industrial dies used to forge automotive steering levers produced in the forging workshop of the Ferrovial Company of Annaba in Algeria. The performance index is given by the number of forged parts corresponding to the reliability index of the dies before failure occurs.

Keywords Forging process $\cdot$ Reliability $\cdot$ Performance index $\cdot$ Critical damage $\cdot$ Industrialization

\section{Introduction}

In the forging industry, a key concern is the die life despite the efforts that have been spent during the last decade in developing high technology to make the production process accurate, reliable and efficient. The duration of the material forming process in one stage is about $0.08 \mathrm{~s}$, and during this time it is very hard to follow or to observe the process [1]. Meanwhile, damaged die is complex and difficult to analyse because of the mutual interactions between the factors involved in the mechanism of hot forming [2]. Bayramoglu et al. [3] have investigated the effect of die coating on die life. The performance of dies has been evaluated on the basis of the ratio of expenses on dies over the number of the products that can be produced in a real production line. Compared to uncoated dies that have been hardened and tempered, the die life for coated dies has been increased, and the best performance is observed for the cobalt weld overlay since the production was $892 \%$ higher and the reduction in cost was of $80 \%$. Wei et al. [4] have based their work on the selection of heat treatment process and the wear mechanism of high wear-resistant $\mathrm{Cr}-\mathrm{Mo}-\mathrm{V}$ hot-forging die steel. They have shown that when an appropriate combination of hardness, toughness and microstructure thermal stability is applied, good wear resistance in high-temperature forging is obtained. Navinšek et al. [5] have used duplex BALINIT ${ }^{\circledR}$ 
FUTURA coatings in order to improve the process of hot forging of steel components. Performance tests conducted on more than 10,000 parts in real working conditions in the UNIOR hot forging industry in Zreče, Slovenia, have revealed that the tool life has been significantly improved compared to single coating. Meanwhile, they could not perform tests after 1050 strokes when micro-cracking and structural changes are induced in the dies; therefore, they suggest laboratory analysis for prediction of tooling performance. Forging simulation offers significant advantages by providing detailed insight into the forging process before tool selection and process decisions are made on the shop floor [6]. The importance of using forging process simulation software in industry in order to solve accurately many practical problems of forging technology has been reported by Tang et al. [7]. Later on, Brucelle and Bernhart [8] have presented a method for service life increase of hot forging tools based on the simultaneous use of numerical simulations and experimental laboratory and industrial tests. The simulations relied on Forge $2^{\circledR}$ computer code for the process, Ideas ${ }^{\circledR}$ software for the meshing and ABAQUS ${ }^{\circledR}$ computer code for the thermal stress calculation. The method has been applied to produce an airbag part made from austenitic stainless steel AISI 316L using punching tools and has shown that the thermal stress induced by sharp thermal gradient during forging corresponded to $75 \%$ of the total stress field, in the areas of die surface cracking. Parametric analysis has allowed optimizing the forging process parameters such as part temperature and punching velocity that lead to producing good parts with better die life.

In the last 15 years, the use of computer-simulated forming process has known great development. Tomov et al. [9] have used the software package FORM-2D in order to improve the process planning and die design and have adapted a new approach for the classification of axis-symmetrical forged parts. Arbak et al. [10] have investigated the production of bearing rings by three hot forging methods. With the help of a commercial finite element software package (MSC/AutoForge) to support their experimental work, using an appropriate shape preformed die, they have found that a reduction of the forming pressure of $15 \%$ is possible and that the tool life increases and die fracture can be prevented. The growing interest of using numerical simulation has been evidenced by Hartley and Pillinger [11] who have provided an overview on the research in the numerical simulation of forging that reports on the importance of re-meshing in realistic forging modelling with regard to the correct die shape, the assessment of die stresses and the analysis of die failure. In the current decade, two main established codes, DEFORM ${ }^{\mathrm{TM}}$ and FORGE ${ }^{\circledR}$, are being used for computer simulation of solid-state metal forming operations. They both offer a large number of parametric analyses for optimizing and settlement of parameters on the forging machine. Choi et al. [12] have developed a method that determines the abrasive wear parameters in order to estimate the die failure. They have demonstrated that the cost and time spent in predicting die failure through experimental work and die tryouts can be minimized with the use of finite element method (FEM) simulations. Equbal et al. [13] have shown that DEFORM $^{\mathrm{TM}}$ 3D FEM-based simulation software was an effective tool in investigating the effect of design and process parameters on forging load and loss of billet temperature. Using potential of Taguchi design of experiments, analysis of variance and the Grey-Taguchi method in multi-objective optimization of process parameters, they have optimized the parameters to better performance of the forging process.

Therefore, the use of design experiment and statistical tools is very interesting when coupled with finite element analyses. For instance, Majerus et al. [14] have presented a reviewing paper showing how to obtain statistically meaningful data from precision closed-die forging experiments, so that accurate and reliable tests can be conducted for different forging simulation programs. It is the case of Snape et al. [15] who have provided a useful forging process guide for quantifying and comparing the sensitivity of thermomechanical parameters to variations in different inputs of the involved parameters such as the flow stress of the forged steel, the heat transfer and the friction at the die-part interface. The analyses of their investigation have followed the model used in FORGE2 ${ }^{\circledR}$ code using full-factorial design of experiment for parametric variation assessment. Allam et al. [16] have conducted Monte Carlo simulations to evaluate the process parameter variations in order to investigate the effect of key parameter variations on product specification deviations. They have proposed a decision support system that helps control the pertinence of the forging process.

In fact, the above review of literature shows how much the die life is economically important and complex to estimate. Therefore, with computer facilities existing nowadays, the research for faster and realistic simulation methodology in order to assess the performance of hot forging dies is required significantly to improve the competitiveness of forging, specifically in improving the in-service life [17].

The above state of the art aimed to present the main important works that have been carried out to overcome the problem of increasing die life. Nowadays, forging simulation tools have known a great development and are becoming very useful and necessarily. In addition, the use of statistical techniques, in combination with numerical simulation FEM codes, has been increasingly registered both in the industrial and academic worlds [18]. The present contribution proposes a new concept of analysing die life using a computer-aided engineering (CAE) tool and a probability and reliability tool. The present work is a contribution in the evaluation of a performance index of hot forging dies based on the combination of a forging process model with a die damage model. The combined model is used to predict the probability of die failure expressed in terms of reliability index $\beta$ according to a 
limit state function of the forging process. The concept of assessment of die performance is first presented and developed. Then, this concept is applied on a real case study in dies used to forge automotive levers produced in the forging workshop of the Ferrovial Company of Annaba in Algeria. The objective is then to integrate a decision tool on the site of the production in order to prevent any failure which can lead to production delays or shutdown.

\section{Concept of die performance}

The present work focuses on a new concept in predicting forging die life based on the reliability PhimecaSoft computing tool [19] that requires a geometrical model of the die, a mechanical engineering model expressing the behaviour of the die during service, the probabilistic laws of the parameters involved within the mechanical engineering model and a limit state function separating the safety domain from the failure domain. The geometrical model of the die is developed from the geometry of the part to be forged. The mechanical engineering model is determined by combining, on one hand, the rheological law included in the forge simulation code and, on the other hand, the damage law for dies given for instance by the Lemaitre and Chaboche law [20]. Then, the reliability assessment follows the procedure described by PhimecaSoft [19]. The results aim to know the probability of failure of dies as a function of the number of forged parts, which should be used as a referential in the industrial site to predict die life. The following description concerns the concept of the present approach.

Nowadays, forming process behaviour is commonly modelled and simulated and analysed by means of forming purpose CAE codes, FORGE ${ }^{\circledR}$ and DEFORM ${ }^{\mathrm{TM}}$. However, despite the efficiency of the CAE tools, the results can be easily altered because of the uncertainties associated with the values of the parameters of the phenomenon involved in the industrial process due to tooling, equipment and process phases. Therefore, in order to estimate more accurately the global performance of the forming process and overcome the effect of the variable uncertainties, reliability tools can bring better explicit information on the forming process. The proposed approach consists of combining the process behaviour model with a damage model to allowing simulations that can predict the probability of failure, which will be used as a decision tool to characterize an industrial performance index. Meanwhile, when assessing the die performance, the respective criteria must be observed, such as qualification for the industry, the degree of confidence in using the purpose-developed combined models and the scenario of failure for predicting the performance index.

The process models rely on computing codes used by forging and forming industries seeking for accuracy and international competition. They are used for carrying out a complete analysis of a forming process and allow (a) Optimizing the factors required for the forging procedure to produce good parts with better life of dies,

(b) Identifying required efforts and stresses applied on dies,

(c) Checking the rate of elastic and plastic deformation and

(d) Checking the thermal cycles of the part and the dies.

When the formulation of the process is carefully done and the empirical models with the related parameters are fairly identified and accurate, the CAE simulation is used for ease of implementation and computing time reduction and can be predictive in offering opportunities to making good decisions when die life is concerned. At this level, only the nominal values of the process parameters are defined. Then, in order to match the uncertainties associated with these nominal values, reliability tools can be applied using FORM/SORM or Monte Carlo methods to make realistic comprehension of the process behaviour. So the main objective of the present concept was to determine the optimal variables that best affect the accuracy of the forging process and control and even predict damage in dies. Figure 1 shows the concept of evaluating the performance index of hot forming dies.

The next part of this paper develops this concept, which is illustrated by an industrial example: assessment of hot forging die life used to produce steering levers.

\section{Identifying die failure from an industrial case}

Steering levers produced in the forging workshop of the Ferrovial Company of Annaba in Algeria can be considered as a good industrial case, which is evident in this present work. The levers made of $34 \mathrm{CrMo} 4$ material are obtained through a procedure that includes heating the billet at $1200{ }^{\circ} \mathrm{C}$, free drawing of a billet, then bending on a $\mathrm{KH} 250$ press machine, reheating to $1200{ }^{\circ} \mathrm{C}$ before pre-forming and final forming on a KH500 Lasco hammer machine. The dies are manufactured from commercial SM2 steel corresponding to X38CrMoV5 steel within the same company. They are preheated at $250{ }^{\circ} \mathrm{C}$. As expected during service, a die is subjected to damage, as shown in Fig. 2, and has to be repaired by grinding and refilling and electrochemical machining. However, it is still very difficult to predict the number of parts at which the die breaks down. The simulation of stamping operation was selected in order to assess the equivalent strain. The simulation objects are presented in Table 1. The die material used for simulation is a $30 \mathrm{CrNiMo} 8$ steel. The parameters of the damage model (Table 2) were found in the work of Thibault Herbland [21].

Figure 2 illustrates the condition of the lower die after producing 2800 parts. Damage zones are observed all around the imprint on the die in three distinctive areas: along the surface of the burrs (Fig. 2a), down in the descendant imprint surface 
Fig. 1 Methodology concept in assessing the performance of hot die forming

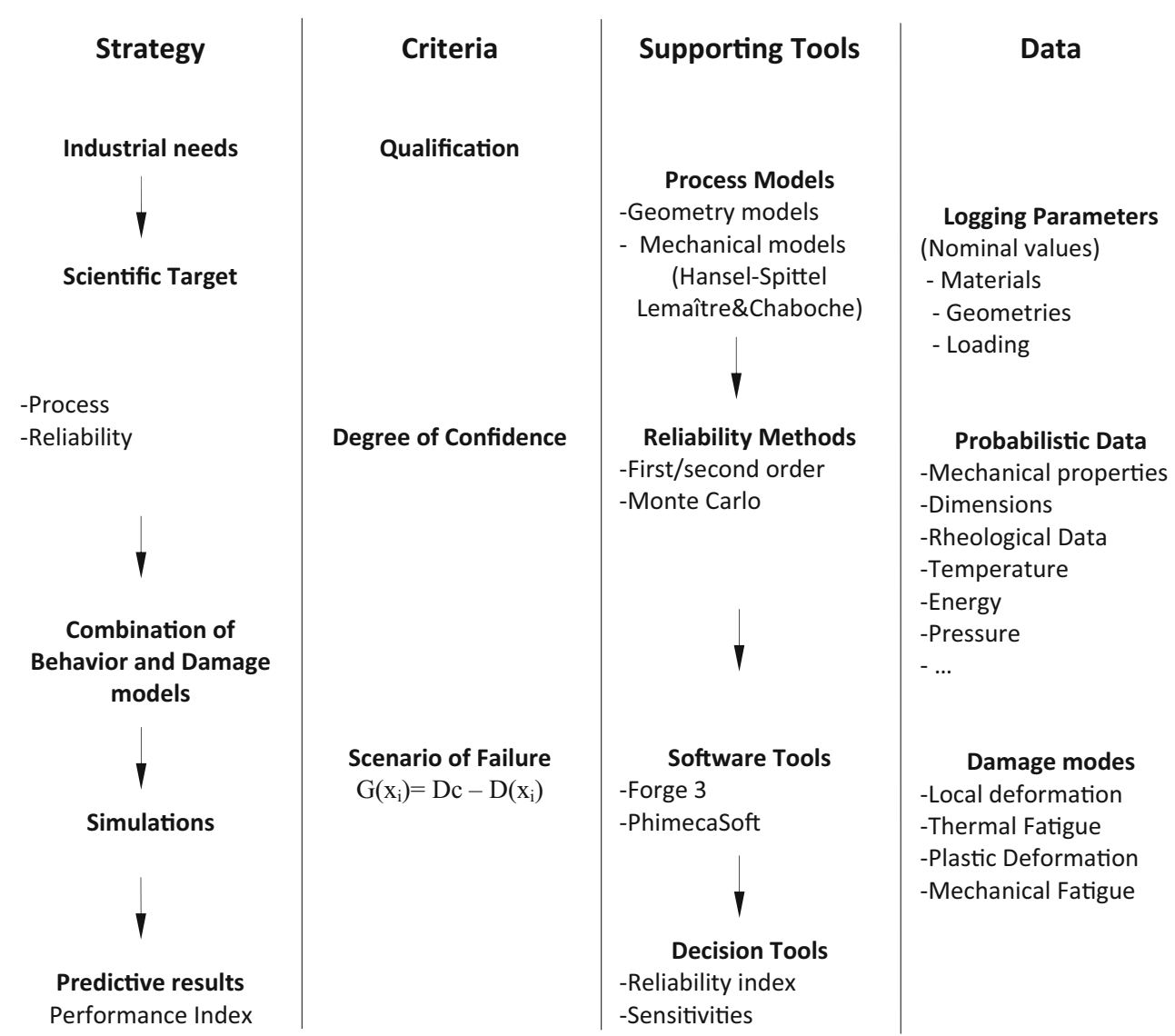

(Fig. 2c) and on the edge (Fig. 2b) contouring the lever imprint. These zones are generated by wear process and plastic

deformation that can be followed by crack propagation, leading to die failure. Even though the stresses may be quite

Fig. 2 Die behaviour after hot forging of steering lever. Surface burrs (la), edge (1b) and descendant imprint damaged zones contouring the steering lever imprint (1c). 2 Milling traces in the burr zone. 3 Plastic deformation. 4 Wear

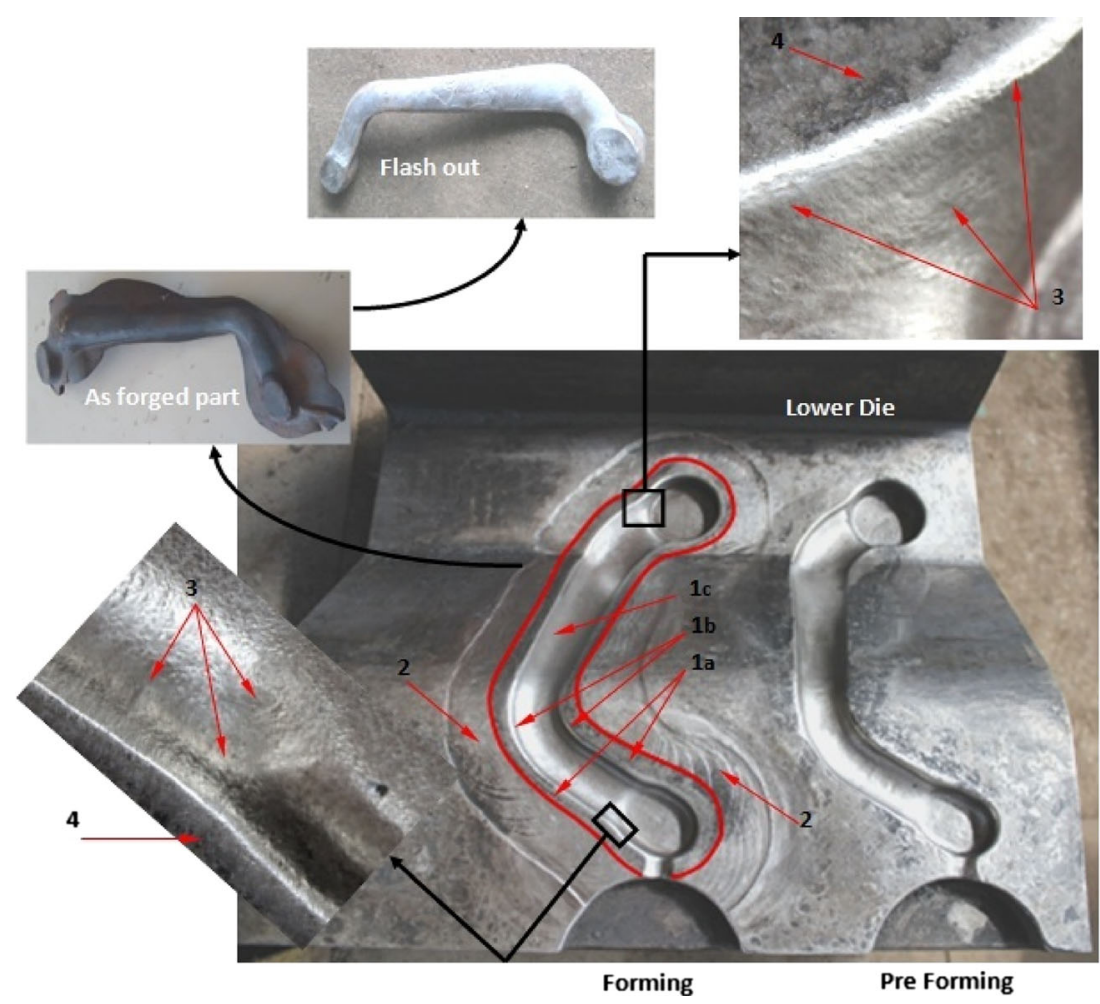


Table 1 Simulation objects

\begin{tabular}{llll}
\hline Objects & Piece & $\begin{array}{l}\text { Deformable } \\
\text { tool 1 }\end{array}$ & $\begin{array}{l}\text { Deformable } \\
\text { tool 2 }\end{array}$ \\
\hline $\begin{array}{l}\text { Description } \\
\text { Material file }\end{array}$ & Billet & Lower die & Upper die \\
$\begin{array}{l}\text { Initial temperature } \\
\left({ }^{\circ} \mathrm{C}\right)\end{array}$ & 1200 & 250 & 30 CrNiMo8.tmf \\
$\begin{array}{l}\text { Mass of billet }(\mathrm{kg}) \\
\text { Mesh size }\end{array}$ & 1.8 & - & 250 \\
\hline
\end{tabular}

negligible, their cumulative effect may lead to fatigue [23]. Usually, it is difficult to prevent when a die fails, particularly when fatigue phenomenon takes place. That is the worst thing that could happen to real-line production, particularly when the die breaks into two parts, as in the case of the die shown in Fig. 3. The lower die has been broken into two parts and then weld repaired in order to reactivate the production. Unfortunately, there has not been a sufficient number of good produced parts, so new dies have been machined. Therefore, a series of die inspection is highly recommended to avoid unpredictable fracture and manage the maintenance of the dies.

\section{Mechanical model for reliability analysis}

The first step in reliability analysis is to determine the physical or mechanical model representing the behaviour of the process. But before that, the process should be geometrically modelled in order to identify the operating parameters of the process. The geometrical model is a determinant in simulating the forging process that allows developing the mechanical model for reliability analysis.

\subsection{Geometrical CAD model}

Steering levers are parts usually presenting a complex morphology, on which much attention should be paid in order to analyse their behaviour during the forming process. Moreover, the more complex the part, the longer the stimulation time. Therefore, in order to minimize the number of parameters to be considered, it has been decided to simplify the geometry of the steering lever as to obtain a core of constant diameter and similar ends. Figure 4 shows the geometrical computer-aided design (CAD) model of the simplified steering lever to be simulated in the present work. The forming procedure which is followed is that one applied in the industry: firstly, cutting a billet; secondly, hot rolling and drawing the lever; and, thirdly, hot cambering the lever then hot forging. All the rheological and forming parameters are determined for a real forging process.

\subsection{Mechanical engineering model}

Die life during hot forging is mainly dependent on resistance to wear, thermal fatigue, plastic deformation and mechanical fatigue. Despite the identification of failure modes on hot forging dies, only a few studies have related the mechanisms of fatigue [24]. The mechanical model aims to define this resistance as a function of different applied loadings: energy, displacements and obvious damage phenomena such as fatigue that is due to fatigue crack growing. The approach then consists of defining a mechanical model combining a forging process model and a damage model. Forging tools perform cycles to determine their damage. Thus, several cycles simulate them one after another up to when fracture is not feasible. In addition, a reliability model is developed to predict the

Table 2 Random variables and corresponding parameters

\begin{tabular}{|c|c|c|c|c|c|c|}
\hline Type of variables & Symbol & Description & $\begin{array}{l}\text { Probability } \\
\text { distribution model }\end{array}$ & Mean value & $\begin{array}{l}\text { Coefficient of } \\
\text { variation }(\%)\end{array}$ & $\begin{array}{l}\text { Source of } \\
\text { information }\end{array}$ \\
\hline Fatigue parameters & $\begin{array}{l}a \\
\beta\end{array}$ & $\begin{array}{l}\text { Constant material } \\
\text { Coefficient of the damage model }\end{array}$ & Normal & $\begin{array}{l}1 \\
2.94\end{array}$ & $\begin{array}{l}1 \\
1\end{array}$ & {$[21]$} \\
\hline Damage parameters & $\begin{array}{l}\sigma_{10} \\
\Delta J\end{array}$ & $\begin{array}{l}\text { Material coefficient } \\
\text { Stress deviator }\end{array}$ & Normal & $\begin{array}{l}480 \\
1121\end{array}$ & $\begin{array}{l}1 \\
1\end{array}$ & $\begin{array}{l}\text { Results from FORGE } \\
\text { simulations }\end{array}$ \\
\hline & $D_{\mathrm{c}}$ & Critical damage & Normal & 0.6 & 16.66 & {$[22]$} \\
\hline $\begin{array}{l}\text { Parameters of the } \\
\text { rheological law }\end{array}$ & $\begin{array}{l}m_{2} \\
m_{3}\end{array}$ & $\begin{array}{l}\text { Material coherence } \\
\text { Sensitivity of material } \\
\text { to temperature } \\
\text { Sensitivity of material to stress } \\
\text { Sensitivity of material } \\
\text { according to strain rate } \\
\text { Sensitivity of material to strain }\end{array}$ & Normal & $\begin{array}{l}1695 \\
262 \times 10^{-5} \\
5618 \times 10^{-5} \\
13,812 \times 10^{-5} \\
4007 \times 10^{-5}\end{array}$ & $\begin{array}{l}0.5 \\
0.5\end{array}$ & $\begin{array}{l}\text { Forming properties } \\
\text { base FPD } 1.3 \mathrm{FORGE}^{\circledR}\end{array}$ \\
\hline Equivalent strain & $\varepsilon$ & $\begin{array}{l}\text { Equivalent strain resulting } \\
\text { from the first cycle of forging }\end{array}$ & Normal & 0.08 & 5 & Results from FORGE ${ }^{\circledR}$ \\
\hline Die temperature & $T$ & Die temperature & & 257 & 2.27 & simulations \\
\hline
\end{tabular}


Fig. 3 Views of weld-repaired lower die for steering lever forging
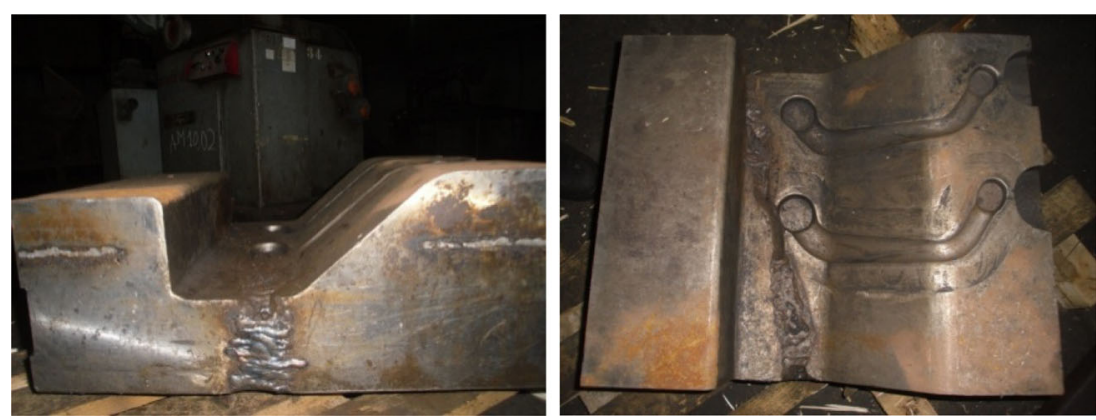

number of cycles to failure. Damage of the LemaitreChaboche law allows calculating directly the life of the tool from certain data from the first cycle forging. It is integrated in the reliability model, and it takes into account the history of the load and also the effect of the mean stress for any stress ratio. In this work, the FORGE software was used. It especially allows simulation of the multi-object forging operation in order to observe the equivalent distortion on a die area. One of the commonly used models in forging code is the rheological Hansel-Spittel [25] model, the law of which applies to viscoplastic behaviour. It is temperature-dependent and takes account of the phenomena of hardening or softening. It takes into account the strain rate of the material. It is presented in [25] and the law given in Eq. 1.

$\sigma=A e^{m_{1} T} \varepsilon^{m_{2}} e^{\frac{m_{4}}{\varepsilon}} \dot{\varepsilon}^{m_{3}}$

where $A$ is the material die coherence, $T$ is the die temperature, $m_{1}$ defines the sensibility of the material to the temperature, $m_{2}$ and $m_{4}$ define the sensibility of the material to strain and $m_{3}$ depends on the sensibility of the material to strain rate.
Meanwhile, the most expressed damage model for fatigue life is that developed by Lemaitre-Chaboche [20, 21].

$N_{f}=\frac{\left\langle\sigma_{u}-J_{\max }\right\rangle}{a(\beta+1)\left\langle\frac{\Delta J}{2}-\sigma_{l}\left(\overline{I_{1}}\right)\right\rangle}\left[\frac{\frac{\Delta J}{2}}{M\left(\overline{I_{1}}\right)}\right]^{-\beta}$

where $\sigma_{\mathrm{u}}$ is the material ultimate stress, $J_{\max }$ is the maximum value of the invariant in von Mises stresses, $a$ and $\beta$ are material coefficients, $\Delta J$ is the stress tensor deviator, $\overline{I_{1}}$ is the mean value of the first tensor stress, $\sigma_{1}\left(\overline{I_{1}}\right)$ is the mean cycling stress range and $M\left(\overline{I_{1}}\right)$ is due to the effect of mean stress, given respectively by Eqs. 3 and 4 .

$\sigma_{l}\left(\overline{I_{1}}\right)=\sigma_{l 0}\left(1-\frac{b \overline{I_{1}}}{\sigma_{\mathrm{u}}}\right)$

$M\left(\overline{I_{1}}\right)=\sigma_{l 0}\left(1-b \frac{\overline{I_{1}}}{\sigma_{u}}\right)$
Fig. 4 a Simplified CAD steering lever. b Cambered part. c Expected steering lever after hot forming
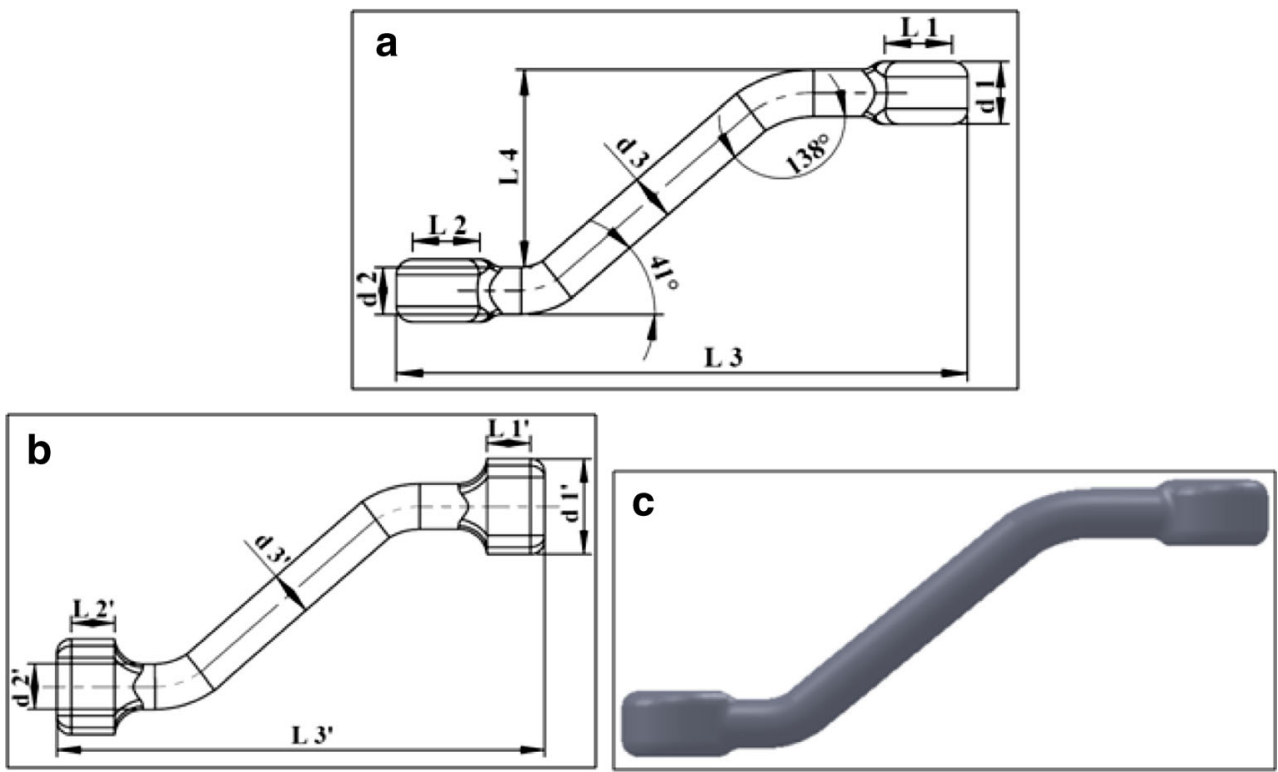
where $b$ and $\sigma_{10}$ are material coefficients.

Then, the above equations are combined in order to define the mechanical engineering model that is to be used in reliability analyses, which is developed as follows:

For a first forging cycle, a first effective strain, $\varepsilon_{f c}$, is generated together with a maximum stress, $\sigma_{f c \max }$, that are replaced in Eq. 1 to get Eq. 5.

$J_{\text {fcmax }}=A e^{m_{1} T} \varepsilon_{\mathrm{fc}}^{m_{2}} e^{\frac{m_{4}}{\xi_{f c}} \varepsilon} m^{m_{3}}$

In terms of stress generated after the first cycle of forging, $J_{\max }$ in Eq. 2 can be replaced by the corresponding stress $\sigma_{\text {fcmax }}$, as expressed in Eq. 6.

$N_{f}=\frac{\left\langle\sigma_{\mathrm{u}}-J_{f c \max }\right\rangle}{a(\beta+1)\left\langle\frac{\Delta J}{2}-\sigma_{l}\left(\overline{I_{1}}\right)\right\rangle}\left[\frac{\frac{\Delta J}{2}}{M\left(\overline{I_{1}}\right)}\right]^{-\beta}$

When replacing $\sigma_{l}\left(\overline{I_{1}}\right)$ and $M\left(\overline{I_{1}}\right)$ by Eqs. 3 and 4, Eq. 6 becomes

$N_{f}=\frac{\left\langle\sigma_{u}-J_{f c m a x}\right\rangle}{a(\beta+1)\left\langle\frac{\Delta J}{2}-\sigma_{l 0}\left(1-b \frac{\overline{I_{1}}}{\sigma_{u}}\right)\right\rangle}\left[\frac{\frac{\Delta J}{2}}{\sigma_{l 0}\left(1-b \frac{\bar{I}_{1}}{\sigma_{u}}\right)}\right]^{-\beta}$
The mean stress, $\overline{I_{1}}$, is given by Eq. 8 when $\sigma_{\text {fcmin }}$ is equal to zero.

$\overline{I_{1}}=\frac{J_{\text {fcmax }}}{2}$

Total damage according to Lemaître-Chaboche [20, 21, 26] is modelled by Eq. 9 .

$D=1-\left[1-\left(\frac{n}{N_{f}}\right)^{\frac{1}{1-\alpha}}\right]^{\frac{1}{\beta+1}}$

where $\alpha$ is a function given by Eq. 10 .

$\alpha\left(\Delta J, \overline{I_{1}}, J_{\text {fcmax }}\right)=1-a\left\langle\frac{\frac{\Delta J}{2}-\sigma_{1}\left(\overline{I_{1}}\right)}{\sigma_{u}-J_{\text {fcmax }}}\right\rangle$

The reliability engineering mechanical model is hence obtained following Eq. 11, which expresses a model correlating the Hansel-Spittel model [25] with the Lemaître-Chaboche model $[20,21,26]$, leading to the mechanical model for reliability analyses.

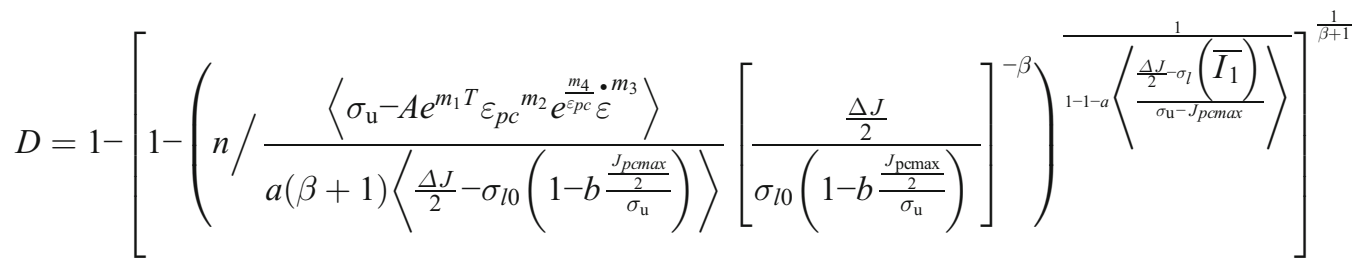

The next step is to construct a failure scenario from Eq. 11 using the reliability approach with limit state functions to assess the performance of dies.

\section{Die performance assessment}

The performance assessment of a die life presenting initiated fatigue damage is achieved using reliability tools in order to determine the remaining life of a die before failure. The latter is expressed in terms of the number of parts produced with the same die regarding the required quality and safety that help in making a decision of replacing or repairing the die. A better performance of the die is presented by the higher number of parts.

\subsection{Limit state function}

Reliability assessment in dies presenting a fatigue damage is based on a damage engineering empirical model determined above in Eq. 11. A limit state function $G(X i)$ is settled for reliability calculation corresponding to the lifetime safety margin defined by the difference between the number of forged workpieces leading to die failure and the required number of workpieces to obtain. This can be expressed through the fatigue damage limit state function (Eq. 12).

$G\left(X_{i}\right)=D_{\mathrm{c}}-D\left(X_{i}\right)$

where $D_{\mathrm{c}}$ is critical damage. The literature according to [22] gives $0.5<D_{\mathrm{c}}>0.7$. 
Failure probability is expressed throughout a reliability in$\operatorname{dex} \beta$, which is defined as the minimum distance between the origin and the failure domain in the equivalent Gaussian space $u_{i}$. This index is evaluated by solving the constrained optimization problem presented in Eq. 13.

$\beta=\operatorname{minimise} \sqrt{\sum_{i} u_{i}^{2}}$ subjected to $G\left(X_{j}\right) \leq 0$

where $u_{i}=T_{i}\left(X_{j}\right)$ is the vector of basic random variables in the standard normal space by appropriate transformation, $T_{i}\left(x_{j}\right)$, and $G\left(x_{j}\right)$ represents the failure surface; in the standard normal space, it takes the form $G\left(T_{j}\left(u_{i}\right)\right)$. The solution of this optimization can be obtained by any standard optimization algorithm. In our case, specific reliability algorithms have been used and combined with a line search procedure. The solution is usually referred to as the design point, noted $u_{i}^{*}$ or $P^{*}$. In a first-order reliability method, the failure probability, $P_{\mathrm{f}}$, is simply calculated by Eq. 14 .

$P_{\mathrm{f}}=P_{\mathrm{r}}[G \leq 0]=\Phi(-\beta)$

where $P_{\mathrm{r}}[\ldots]$ is the probability operator and $\Phi(\ldots)$ is the cumulative Gaussian probability function.

In this work, the performance is attributed to five main factors: the rheological parameters, the fatigue damage parameters, die temperature, strain and the critical damage value. Each factor is characterized and expressed by random variables.

\subsection{Determination of uncertainties}

To evaluate the failure probability, a traditional deterministic approach is not able to take into account the uncertain physical variations related to material properties, friction conditions, tool active surfaces, status, loading conditions, temperatures, etc., as reported by Del et al. [27]. Therefore, random uncertainties must be considered when decisions have to be taken. In the present work, there are considerable uncertainties associated with the engineering mechanical model. In the present session, in order to determine the probabilistic distribution of the parameters included in the mechanical model, each parameter is variably typified, as illustrated in Table 2. In fact, there are three main types of variables: (1) fatigue and damage parameters, (2) parameters of the rheological law and (3) equivalent strain and die temperature resulting from forging simulations. Then, the probabilistic law for each variable has been added, thanks to PHIMECASoft that allows setting the values of the coefficient of variation, leading to the convergence of the results. These uncertainties result from geometry, loading, energy, temperature, forging and service parameters as described in the mechanical model. The parameters are implicitly predicted and optimized throughout their mean values after the forging process simulation by using CAE code FORGE $^{\circledR}$; meanwhile, their associated uncertainties are evaluated using the random variables that enhance explicitly the forging process. In the present work, uncertainties are determined for developing the mechanical model presented by Eq. 11. The rheological Hansel-Spittel model's uncertainties are attributed to the parameters $A, T, m_{1}, m_{2}, m_{3}$ and $m_{4}$, together with strain. In the Lemaitre and Chaboche fatigue damage model for dies, in addition to uncertainties associated with the coefficient parameters $a, \beta$ and $\sigma_{10}$ uncertainties are also included to the stresses generated after the forging operation. These are derived from the von Mises stress given by FORGE ${ }^{\circledR}$ simulation results, such as the values of $\Delta J, \sigma_{\mathrm{u}}$ and $J_{\max }$. Evermore, the values of $\varepsilon, T, \sigma_{\mathrm{u}}$ and $J_{\max }$ are also determined from the simulations by FORGE ${ }^{\circledR}$. The former approach is for finding out the respective values of these strains and stresses which, most of the time, are associated with uncertainties that should be considered. To achieve this, 3D hammer hot forming modelling and simulations have been carried out to form a steering lever made of 34CrMo4 steel, which has been pre-formed before hammering between dies made of 55CrNiMo4 steel. Rheological values and mechanical properties have been introduced from the forming properties database FORGE ${ }^{\circledR}$ code. The aim of the simulations was to determine the first equivalent strain in order to estimate the die life. This is particularly due to the fact that the von Mises stress isovalue is not cumulative and does not quantify the plastic strain, whereas the equivalent isovalue of the equivalent strain is cumulative, and as the final step of the simulation is reached, it allows observing all the zones that have been elastically and/or elastoplastically deformed. In fact, forging dies perform cycles to determine their damage. Thus, simulating several cycles, one after another, it would be possible to see whether the plastic deformations will stabilize, worsen or if new zones come into plasticity. However, simulating several cycles up to failure is difficult to realize since simulating more than four to six cycles requires great computer time and can be very costly for CPU time. There exist fatigue laws that allow directly calculating the lifetime of the dies from data generated from the first forging cycles [22]. Forge Software offers the possibility of running iterative simulations, as explained in [22]. The successive strokes are made with uncoupled calculations. The purpose of this simulation was to link several forging cycles to observe the mechanical tools. Decoupled calculation can quickly perform calculations on the tool and retrieve the results as initial data for a second calculation of the same type. One can thus make a chain of several calculations decoupled to go to the stable mechanical system, providing that the tool temperature is preserved whilst stamping. Figure 5 shows the operating principle of the cycling simulation process setup under Forge software.

One negative of the previous calculation is that the temperature map does not evolve during cycles. One can imagine, as 
Fig. 5 Diagram of the operating principle of cycling simulations under FORGE software

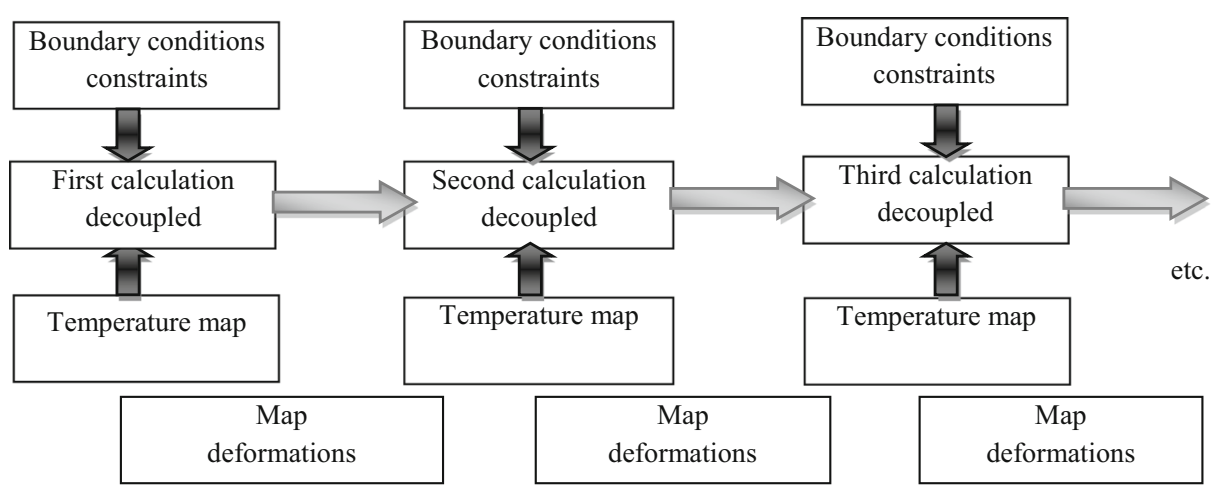

for the mechanical calculation, saving the thermal exchange of single-domain calculation and then reusing or decoupling in use the temperature map of the established thermal regime [22]. Moreover, a series of iterative simulations can be carried out in order to observe the evolution of the effective strain, but this is time-consuming when a great number of iterations are required. So the file friction and heat exchange are selected from the base FPD1.3 of the Forge Software and given in Table 3. A good interpretation of the behaviour of the stress strain is given in the methodological guide for analyses and computing of dies with FORGE ${ }^{\circledR}$ software on the use of forging simulation tools [28]. Simulation results showed that the die deforms plastically in the first five or six forging strokes or cycles and then the deformation becomes fully elastic. Table 4 illustrates the values of strain evolution. It is therefore relatively important to sort out the first five or six iterations for determining, on one hand, the most affected zone and, on the other hand, the maximum value of the effective strain before reaching the minimum value of the effective plastic strain. This latter suggests that the zone is sufficiently damaged to initiate fatigue damage. Figure 6 shows the results of the evolution of the effective elastic strain in the lower die submitted to $250{ }^{\circ} \mathrm{C}$ heat before forming, obtained from the first four iterative simulations.

A strain range of 0-0.04 has been determined to show the evolution of the iterative simulations. Each iteration is represented by a chronological number, allowing seeing at each stage the strain behaviour. Figure 6 (panels $1 b, 2 b, 3 b$ and $4 \mathrm{~b})$ shows the global strain increasing as a function of iterations. The mean strain value is around 0.016 . When observing in detail, the elastic strain value of 0.04 appears on the corner fillets of the upper head and lower head of the grave, as observed respectively in Fig. 6, panels 1a and 1c. However, it is more established on the upper head than in the lower head, and there is a clear distinction between the affected zones as the number of iterations is increased. The maximum value of the strain within a limit of plastic deformation is observed when increasing the range values up to 0.08 , which is considered in the next part of the present work as the minimum value that can initiate fatigue damage. The method of researching the corresponding values is visual and usually includes uncertainties due to misfitting or poor observation and lack of attention, resulting in uncertainties that could be estimated to $5 \%$. Temperature distribution is also observed for the iterative simulations, as shown in Fig. 7. From the start-up of the simulations, an increase of temperature from the initial values of $250-265{ }^{\circ} \mathrm{C}$ is obtained in the zone where the contact part die is most effective (Fig. 7, panel 1d). The uncertainties are therefore evaluated from the effective range of temperature values to give a coefficient of variation of $2.27 \%$. As expected, there has been an increase of the region affected by the increase of temperature after the first four iterative simulations. Other uncertainties that should be included are those associated with the critical damage, $D_{\mathrm{c}}$, since it is difficult to determine the local zone of damage. Because of lack of information, the uncertainties in $D_{\mathrm{c}}$ can be calculated from the suggested values in the literature [27, 29], and that gives a coefficient of variation of $16.66 \%$.
Table 3 Friction and heat exchange models between the billet and dies

\begin{tabular}{lllll}
\hline & Billet & Lower die & Upper die & \\
\hline Lower die & - tresca-fort.tff & - & - tresca-fort.tff & Friction \\
& - hot-steel-fort.tef & & - hot-steel-fort.tef & Heat exchange \\
Upper die & - tresca-fort.tff & - tresca-fort.tff & - & Friction \\
& - hot-steel-fort.tef & - hot-steel-fort.tef & & Heat exchange \\
Door lower die & - & - tresca-fort.tff & - & Friction \\
& - & - hot-steel-fort.tef & & Heat exchange \\
Door upper die & - & - & - tresca-fort.tff & Friction \\
& & & - hot-steel-fort.tef & Heat exchange \\
\hline
\end{tabular}


Table 4

Values of strain evolution

\begin{tabular}{lll}
\hline & Number of cycles & Strain evolution \\
\hline First stroke & 1 & 0.08 \\
Second stroke & 2 & 0.11 \\
Third stroke & 3 & 0.08 \\
Fourth stroke & 4 & 0.095 \\
Fifth stroke & 5 & 0.13 \\
Fifth stroke & 6 & 0.14 \\
\hline
\end{tabular}

The plastic range appear from a deformation of 0.11

\section{Effect of random variables on die performance}

\subsection{Reliability assessment of a die under initiated fatigue damage}

In this case, reliability is evaluated as a function of 12 independent random variables (Table 2).
The reliability software PHIMECASoft ${ }^{\circledR}$ allows computing the reliability index $\beta$ and the failure probability $P_{\mathrm{f}}$. PHIMECASoft is a general probabilistic software dealing with both FORM and SORM approximations and sampling methods applied today to statistic problems. It has the ability to be coupled to a wide spectrum of other engineering software tools and can be viewed as a top layer that pilots a physical model. The process consists essentially of making evident how mechanics and reliability are combined. The literature [19] offers some good aspects of the bases of PHIMECASoft.

Figure 8 illustrates the reliability index evolution as a function of the number of forged parts. The results show that increasing the number of forged parts up to 1800 decreases drastically the reliability of the die. For the three accepted levels of failure probability, $P_{\mathrm{f} 1}=10^{-4}, P_{\mathrm{f} 2}=10^{-5}$ and $P_{\mathrm{f} 3}=10^{-6}$ (corresponding to the reliability indices $\beta_{1}=3.72$, $\beta_{2}=4.27$ and $\beta_{3}=4.75$ ), the respective number of forged parts decreased from 1502, 1371 and 1239 by a step of 130 parts.
Fig. 6 Strain evolution after the first four iterative simulations in a lower die preheated at $250{ }^{\circ} \mathrm{C}$

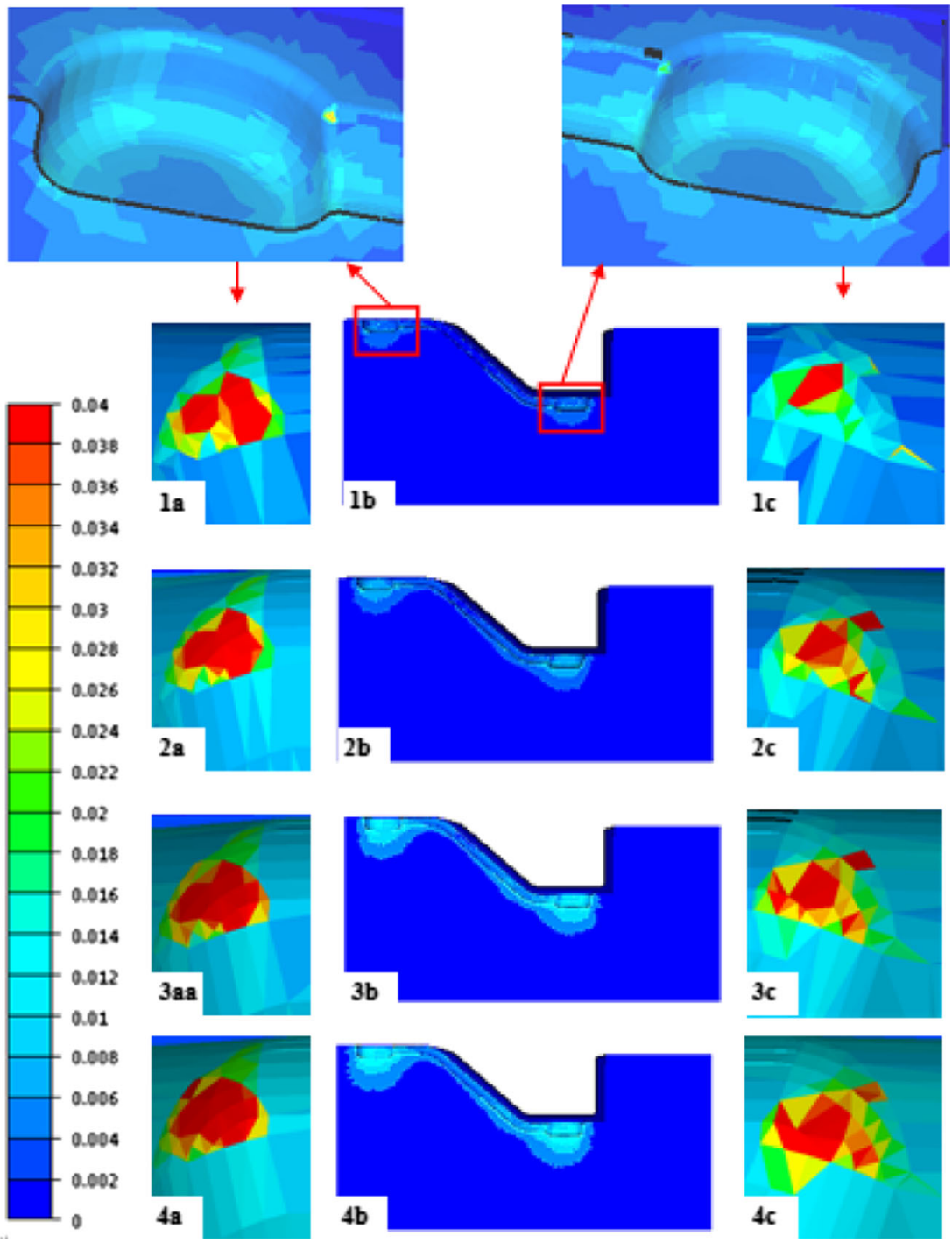


Fig. 7 Temperature distribution and evolution obtained after four iterative simulations
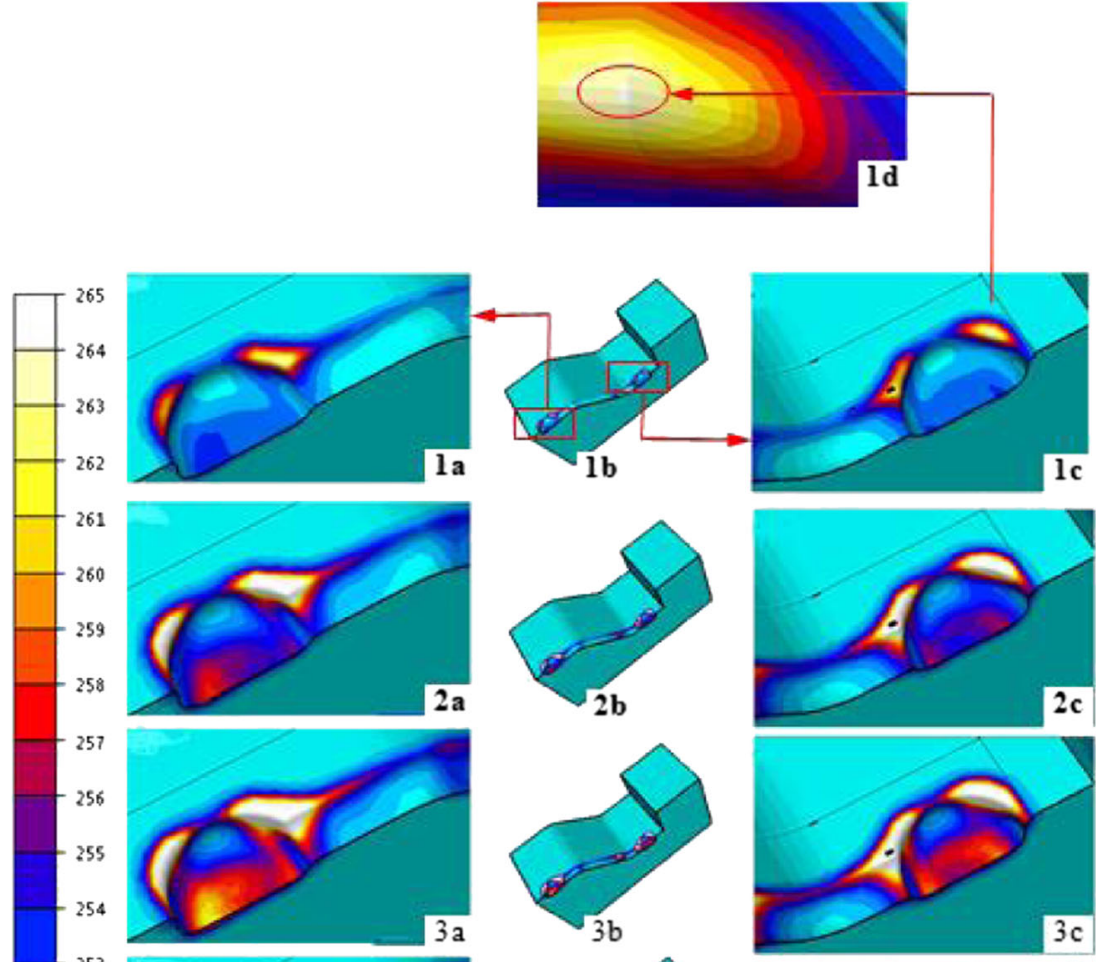

253
252
251
250
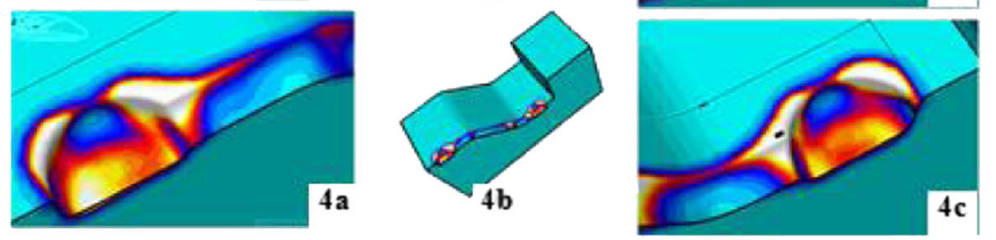

From the point of view of cost, it is now easy to find out how much loss can be avoided when a decision is to be made regarding replacing the damaged die with a repaired one or a new one. The final decision returns to both maintenance and exploitation services, which should be able to observe the evolution of the cost index according to the quality of the parts, the delivery time, the risk of damaging the die and the

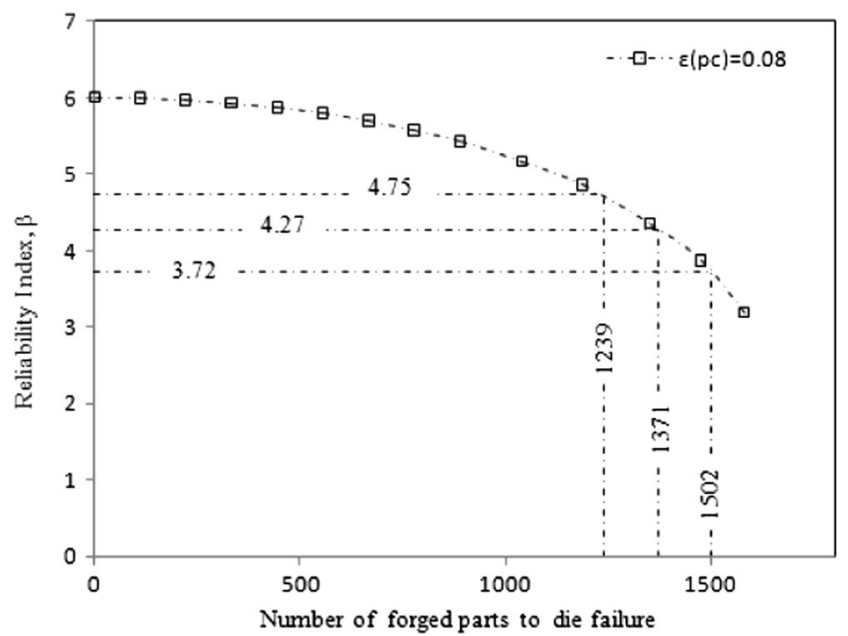

Fig. 8 Evolution of reliability index $\beta$ as a function of number of forged parts in hot die presenting a fatigue damage for $\varepsilon(\mathrm{pc})=0.08$ mean cost of replacing the damaged die. This cost index due to die life can then be considered as a performance index.

\subsection{Variable sensitivities}

The variable sensitivity $\alpha^{2}$ or the contribution of random variables on the die life is shown in Fig. 9 for an accepted value of

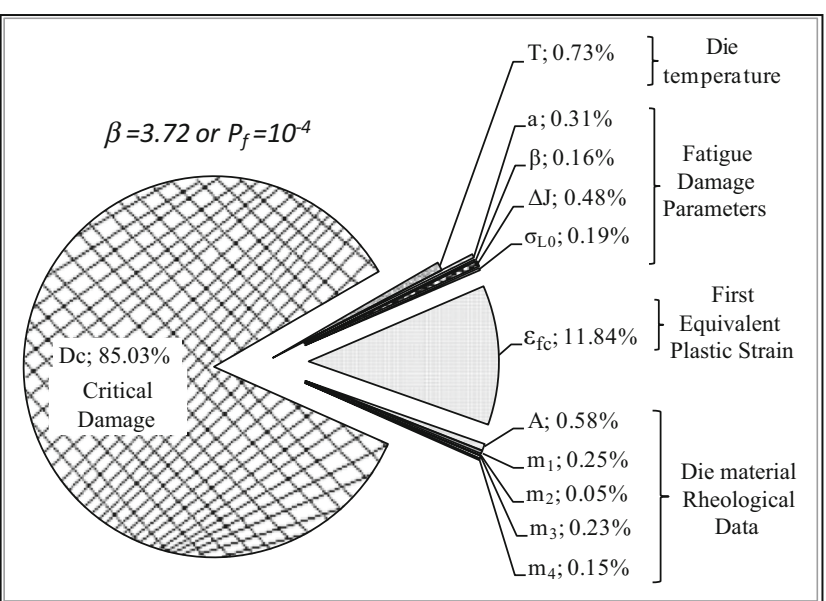

Fig. 9 Importance of the variables in a hot die forming (random variables and parameters according to Table 2) 
reliability index $\beta$ of 3.72 , when the number of forged parts increases up to 1502 . There are five main factors that can be considered controlling the die life: the critical damage $D_{\mathrm{c}}$, the die temperature $T$, the rheological parameters of the die material, the equivalent plastic strain after one cycle and the fatigue damage parameters. The most important variable is obviously the critical damage, $D_{\mathrm{c}}$, which represents $85.03 \%$ of all global parameters. The equivalent strain follows with less than $12 \%$; the rest is attributed to all other parameters.

When increasing the level of the accepted probability of failure, critical damage takes much more importance as the accepted level of the probability failure, and it becomes most dominant with $93.62 \%$ (Table 5) for a level of probability of failure value of $10^{-6}$. The progression of this dominance is shown in Fig. 10, which represents the evolution of variable sensitivities as a function of the accepted value of probability of failure in a die designed for hot lever forming.

\subsection{Effect of temperature sensitivity and temperature}

Whenever forging is concerned, die temperature is still one of the most important factors to control since it can be easily impacted during the forging process. As far as uncertainties are concerned within the present work, great care should be made in choosing the material parameters and the mechanical low controlling the die life. The basic concept developed in Fig. 8 shows that even when considering a good tool in simulating a forming process, there is a significant influence of the random variables of die life. Ahead of fatigue damage, obviously critical damage is dominant, for a mean temperature of $257^{\circ} \mathrm{C}$ with a coefficient of variation of $2.7 \%$, determined from one simulation ranging from 249 to $265^{\circ} \mathrm{C}$ (Fig. 4). A determinist investigation of temperature makes more sense in analysing the effect of temperature on die life.

\begin{tabular}{lllll} 
Table 5 Evolution of & & & & \\
\cline { 2 - 4 } variable sensitivity, $\alpha^{2}$ & $P_{\mathrm{f}}$ & $10^{-4}$ & $10^{-5}$ & $10^{-6}$ \\
(design point in the & $\beta_{\text {eav }}$ & 3.72 & 4.27 & 4.75 \\
reduced space), as a & Variable & $\alpha^{2}(\%)$ & & \\
function of accepted & $T$ & 0.73 & 0.55 & 0.33 \\
levels of probability of & $a$ & 0.31 & 0.23 & 0.14 \\
failure, $P_{\mathrm{f}}$ & $\beta$ & 0.16 & 0.10 & 0.05 \\
& $\Delta J$ & 0.48 & 0.19 & 0.01 \\
& $\sigma_{10}$ & 0.19 & 0.06 & 0.00 \\
& $\varepsilon_{\mathrm{pc}}$ & 11.84 & 8.74 & 5.26 \\
& $A$ & 0.58 & 0.46 & 0.27 \\
& $m_{1}$ & 0.25 & 0.20 & 0.12 \\
& $m_{2}$ & 0.05 & 0.04 & 0.02 \\
& $m_{3}$ & 0.23 & 0.18 & 0.11 \\
& $m_{4}$ & 0.15 & 0.11 & 0.07 \\
& $D_{\mathrm{c}}$ & 85.03 & 89.13 & 93.62 \\
\cline { 2 - 5 } & $\beta_{\text {eav }}$ engineering acceptable value
\end{tabular}

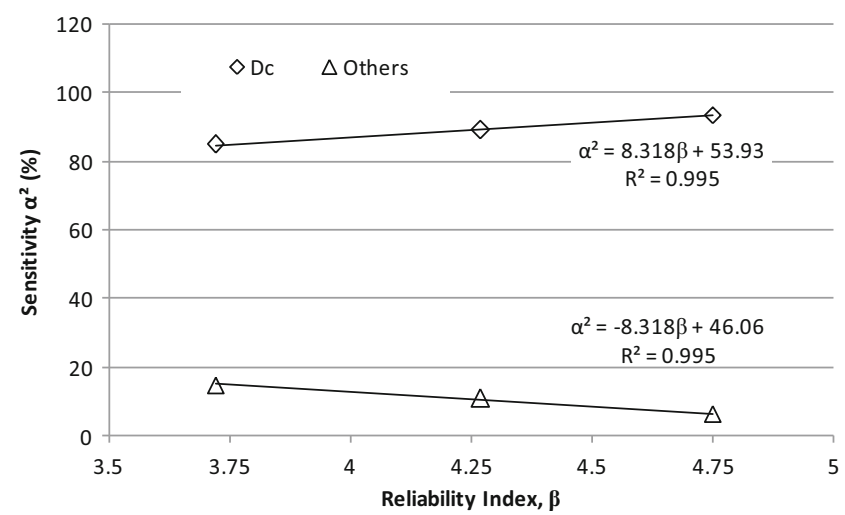

Fig. 10 Evolution of variable sensitivities as a function of accepted level of probability failure in a die for steering lever forming

Figure 11 illustrates the evolution of the reliability index $\beta$ as a function of number of forged parts at different deterministic values of die temperature ranging from 240 to $280{ }^{\circ} \mathrm{C}$. This range has been selected to satisfy the results obtained from FORGE ${ }^{\circledR}$ simulation that allows the first equivalent strain of $\varepsilon(\mathrm{pc})$ of 0.08 .

For a $\beta$ level of 3.72, it is interesting to see that the number of forged parts increases by steps of 90 parts as the die temperature is subjected to an incremental decrease of $10^{\circ} \mathrm{C}$ from 280 to $240{ }^{\circ} \mathrm{C}$. However, this does not lead to reasonably suggesting to drop the die temperature as the main simulation temperature mapping should be respected (Fig. 7). In fact, at the commonly used die temperature of $250{ }^{\circ} \mathrm{C}$, the number of forged parts reaches 1650 , which gives 148 extra parts compared to when using a die temperature of $257^{\circ} \mathrm{C}$, with a coefficient of variation of $2.7 \%$. Hence, the risk of die failure is increased.

\subsection{Effect of first effective strain}

The effect of temperature on die life is correlated with the value of the first effective strain, on which much attention should be paid when evaluating it. For instance, in the conditions given in Table 2, this value is 0.08 , with a coefficient of variation of $5 \%$. If the die material properties come to be altered for any reason, leading to a change in the first equivalent strain, then deterministic values can be applied to evaluate die life. Therefore, an investigation of the influence of the first equivalent strain on die life can be explored to find how much effect this can bring. Figure 12 shows the evolution of the reliability index $\beta$ as a function of a number of forged parts when the first equivalent strain increases from 0.06 to 0.1 by increments of 0.02 , according to a die temperature of $257^{\circ} \mathrm{C}$ with a coefficient of variation of $2.7 \%$.

A drop of the value of the equivalent strain by an increment of 0.02 , from 0.08 to 0.06 , generates a gain of 700 parts, which is very important, but an increase by the same increment leads to a drastic decrease in the number of forged parts to die 
Fig. 11 Estimation of die life through the evolution of the reliability index $\beta$ as a function of temperature

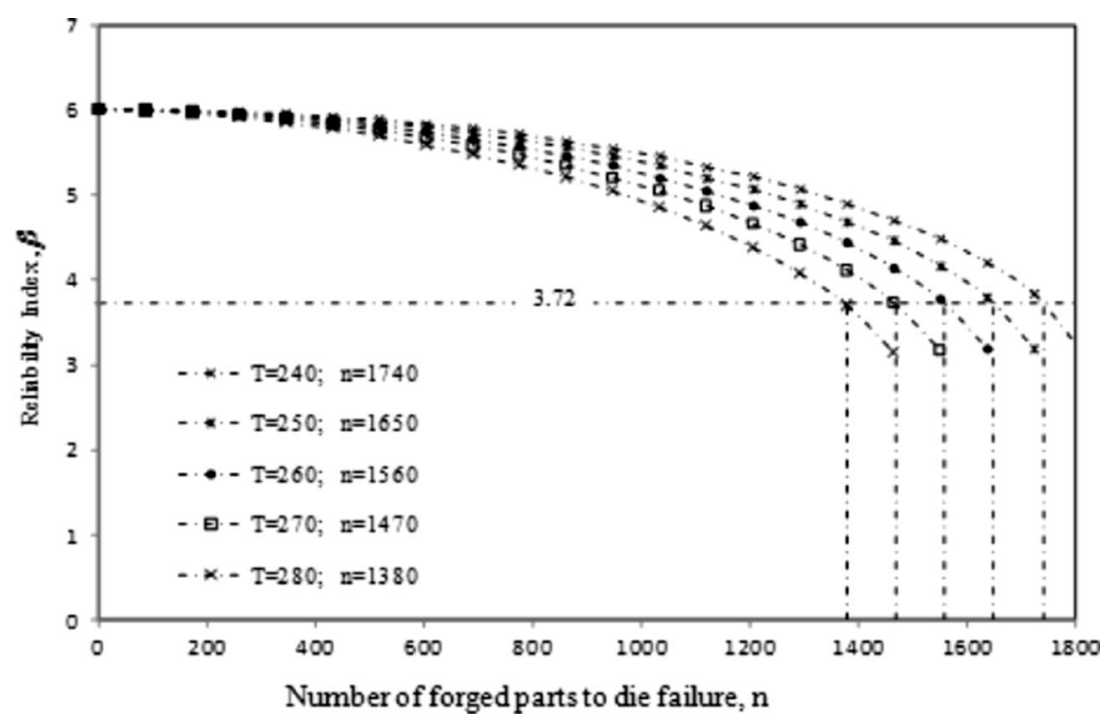

failure. A correlation can be established between the equivalent first strain and the number of forged parts to die failure and follows an exponential law of the form given the fitting curve obtained in Fig. 13.

\section{Conclusions}

The performance index of a hot forging process has been investigated through the assessment of the lifetime of dies used to forge steering levers on a 500-T hammer machine. In addition to the parameters and conditions of hot forging, as soon as hammering starts, the die is subjected to a small equivalent strain that could generate zones of damage, particularly a fatigue crack growth. The only way to detect damage is by inspecting the topography of dies, specifically in the sensitive zones, as revealed by the results of the present

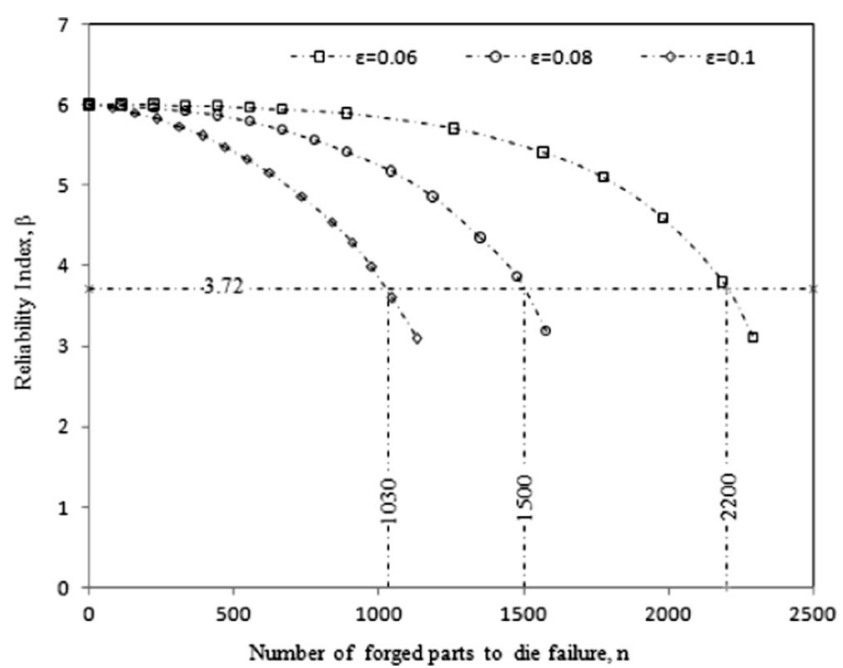

Fig. 12 Estimation of die life through the evolution of reliability index $\beta$ as a function of first equivalent strain forging simulations. The forming process CAE code, FORGE $^{\circledR}$ and the reliability software PHIMECASoft ${ }^{\circledR}$ have been used to perform the present investigation. An engineering empirical model combining the forging process model with a fatigue damage model has been developed and characterized with random variables in order to analyse the die life. The main results can be summarized as follows:

1. The die life empirical model is developed by correlating the Hansel-Spittel and Lemaître-Chaboche models. This allows formulation of the forming process of a die under initiated fatigue damage.

2. The forming process simulations have implicitly predicted the relative parameters in terms of input data, such as geometry parameters, rheological parameters, temperatures, loading conditions and energy, and output data, such as von Mises stresses, first equivalent strain, changes in temperature during the forming process, wear and thermal plastic deformation. The reliability analyses consist of explicitly predicting the probability of failure from the empirical model. The involved parameters are associated

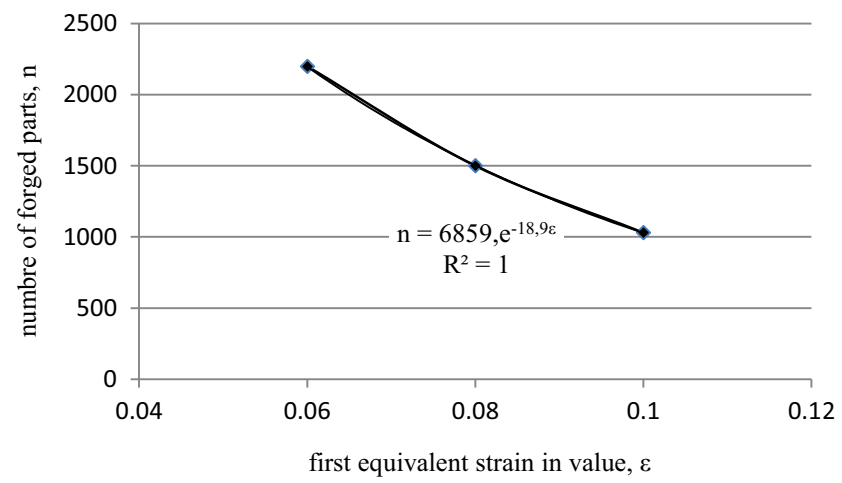

Fig. 13 Evolution of the number of forged parts as a function of first equivalent strain 
with their uncertainties, which have been characterized by their probability of density. A limit state function has been set as the difference between the critical damage and the value of the propagating damage. Results are expressed in terms of the reliability index $\beta$ and variable sensitivities.

3. The performance index of a die is attributed to the number of forged parts at which die failure occurs. Performance is expressed as: the greater the number of forged parts, the longer the die life. In the present work, five main factors have been considered, i.e. die material rheological parameters, Lemaître and Chaboche fatigue damage model, die temperature, first equivalent strain and critical damage.

4. The performance index of a die can be deduced from the reliability results. For a reliability index $\beta=3.72$, a number of 1502 parts can be produced with safety. So the performance index is 1502 when the die temperature is set to $257^{\circ} \mathrm{C}$, a first effective strain of 0.08 is observed from inspection and the critical damage value is fixed to 0.6 , associating their respective coefficient of variation of $2.7 \%$ and with 5 and $13.5 \%$.

5. As expected, critical damage is the most important variable, with a sensitivity of $85 \%$ for a reliability index of 3.72. The next most sensitive parameter is the first equivalent strain, with $11 \%$ importance.

6. Deterministic investigations of temperature and first equivalent strain have led to interesting behaviour of the die life towards the respective random variables. When increasing the die temperature by steps of $10^{\circ} \mathrm{C}$ from 240 to $280{ }^{\circ} \mathrm{C}$, whilst the first strain is 0.08 with a coefficient of variation of $5 \%$, the performance index decreases by steps of 90 parts, from 1740 to 1380 . Meanwhile, when increasing the first equivalent strain by steps of 0.02 from 0.06 to 0.1 and setting the die temperature at $257^{\circ} \mathrm{C}$ with a coefficient of variation of $2.5 \%$, a drastic degradation of the die life is generated.

7. The sooner a crack is detected in a die, the better is the evaluation of the performance index. This requires frequent inspections of the surface of the dies. In fact, if there is no crack, and as far as the control of the process is done well, then the tool will achieve the number of parts for which it was designed; otherwise, the results of this present work are very indicative.

Acknowledgments The authors would like to thank the Forge de l'Est of Ferrovial Company in Annaba, Algeria. Financial supports are due to the national research project DGRSDT Algeria, code CSCU232010 (www.dgrsdt.dz).

\section{References}

1. Šraml M, Stupan J, Potrč I, Kramberger J (2004) Computer-aided analysis of the forging process. Int J Adv Manuf Technol 23:161168
2. Alimi A, Fajoui J, Kchaou M, Branchu S, Elleuch R, Jacquemin F (2015) Multi-scale hot working tools damage (X40CrMoV5-1) analysis on relation to the forging process. Eng Fail Anal 62:142155

3. Bayramoglu M, Polat H, Geren N (2008) Cost and performance evaluation of different surface treated dies for hot forging process. J Mater Process Technol 205(1-3):394- 403

4. Wei MX, Wang SQ, Wang L, Cui XH, Chen KM (2012) Selection of heat treatment process and wear mechanism of high wear resistant cast hot-forging die steel. J Iron Steel Res Int 19(5):50-57

5. Navinšek B, Panjan P, Gorenjak F (2001) Improvement of hot forging manufacturing with PVD and DUPLEX coatings. Surf Coat Technol 137:255-264

6. Khalilpourazary S, Dadvand A (2011) Design and manufacturing of a straight bevel gear in hot precision forging process using finite volume method and CAD/CAE technology. Int J Adv Manuf Technol 56:87-95

7. Tang J, Wu WT, Waiters J (1994) Recent development and applications of finite element method in metal forming. J Mater Process Technol 46(1-2):117-126

8. Brucelle O, Bernhart G (1999) Methodology for service life increase of hot forging tools. J Mater Process Technol 87:237-246

9. Tomov BI, Gagov VI, Radev RH (2004) Numerical simulations of hot die forging processes using finite element method. J Mater Process Technol 153-154:352-358

10. Arbak M, Tekkaya AE, Ozhan F (2005) Comparison of various preforms for hot forging of bearing rings. J Mater Process Technol 169:72-82

11. Hartley P, Pillinger I (2006) Numerical simulation of the forging process. Comput Methods Appl Mech Eng 195(48-49):6676-6690

12. Choi C, Groseclose A, Altan T (2012) Estimation of plastic deformation and abrasive wear in warm forging dies. J Mater Process Technol 212(8):1742-1752

13. Equbal MI, Kumar R, Shamim M, Ohdar RK (2014) A Grey-based Taguchi method to optimize hot forging process. Procedia Mater Sci 6(ICMPC):1495-1504

14. Majerus JN, Jen KP, Gong H (1997) Quantitative data for precision, closed-die, forging: internal deformations and computer simulations. Int J Mach Tools Manuf 37(4):523-554

15. Snape G, Clift S, Bramley A (2002) Parametric sensitivity analyses for FEA of hot steel forging. J Mater Process Technol 126:353-360

16. Allam Z, Becker E, Baudouin C, Bigot R, Krumpipe P (2014) Forging process control: influence of key parameters variation on product specifications deviations. Procedia Eng 81:2524-2529

17. Lavtar L, Muhič T, Kugler G, Terčelj M (2011) Analysis of the main types of damage on a pair of industrial dies for hot forging car steering mechanisms. Eng Fail Anal 18(4):1143-1152

18. Strano M (2007) A simplified methodology for estimating the variance of material properties. In: FE analysis under uncertainty of sheet and tube metal forming processes. AIP Conference Proceedings 908(1):499-504

19. Lemaire M, Pendola M (2006) PHIMECA-SOFT. J Struct Safe 28: $130-149$

20. Lemaitre J, Chaboche JL (1990) Mechanics of solid materials. Cambridge University Press, Cambridge

21. Herbland T (2009) Une méthode de correction élastoplastique pour le calcul en fatigue des zones de concentration de contraintes sous chargement cyclique multiaxial non proportionnel. Thèse de doctorat, Mechanics. École Nationale Supérieure des Mines de Paris, France

22. CETIM (2009) Centre Technique des Industries Mécaniques, Guide méthodologique d'analyse pour les calculs des outillages avec le logiciel Forge. Code AP no. 015366. www.cetim.fr 
23. Njeh F, Kchaou M, Elleuch R, El Halouani F (2012) Analysis of degradation and failure mechanisms that develop in hot forging die. J Fail Anal Prev 12(3):273-280

24. Kchaou M, Elleuch R, Desplanques Y, Boidin X, Degallaix G (2010) Failure mechanisms of H13 die on relation to the forging process - a case study of brass gas valves. Eng Fail Anal 17(2): 403-415

25. Hansel A, Pittel T-S (1979) Kraft- und Arbeitsbedarf BildsomerFormgeburgs Verfahren. VEB Deutscher Ver-lang fur Grundstoffindustrie, Lipsk
26. Lemaître J, Chaboche JL (2014) Mechanics of solid materials. Cambridge University Press, Cambridge

27. Del A, Primo T, Strano M (2010) The use of FEA packages in the simulation of a drawing operation with springback, in the presence of random uncertainty. Finite Elem Anal Des 46(7): 527-534

28. Bramley AN, Mynors DJ (2000) The use of forging simulation tools. Mater Des 21(4):279-286

29. FORGE3R (2002) FORGE3R reference guide release 6.2, SophiaAntipolis 